\title{
Peroxiredoxin Expression of Human Osteosarcoma Cells Is Influenced by Cold Atmospheric Plasma Treatment
}

\author{
DENIS GÜMBEL ${ }^{1,2}$, NADINE GELBRICH ${ }^{1}$, MATTHIAS NAPP ${ }^{1}$, GEORG DAESCHLEIN $^{4}$, AXEL KRAMER ${ }^{5}$, \\ AXEL SCKELL ${ }^{1}$, MARTIN BURCHARDT ${ }^{3}$, AXEL EKKERNKAMP ${ }^{1,2}$ and MATTHIAS B. STOPE ${ }^{3}$ \\ Departments of ${ }^{1}$ Trauma, Reconstructive Surgery and Rehabilitation Medicine, \\ ${ }^{3}$ Urology, ${ }^{4}$ Dermatology, and ${ }^{5}$ Hygiene and Environmental Medicine, \\ University Medicine Greifswald, Greifswald, Germany; \\ ${ }^{2}$ Department of Trauma and Orthopaedic Surgery, BG Klinikum \\ Unfallkrankenhaus Berlin gGmbH, Berlin, Germany
}

\begin{abstract}
Background/Aim: To evaluate the potential involvement of redox-specific signalling pathways in cold atmospheric plasma (CAP)-induced apoptosis on human osteosarcoma cells. Materials and Methods: Osteosarcoma cell lines were treated with CAP with or without antioxidative agents and seeded in cell culture plates. Cell proliferation was determined by counting viable cells. Carrier gas-treated cells served as control. Peroxiredoxin (PRX) 1-3 expression and secretion were assessed. Results: $C A P$ treatment exhibited strongly attenuated proliferation rates. This effect was significantly attenuated by the addition of $N$-acetylcysteine (NAC). CAP-treated cells exhibited an increase of PRX 1 and 210 sec after treatment. The ratio of oxidized to reduced PRX1 and PRX2 was significantly altered with increasing cellular concentration of the oxidized dimer. Conclusion: Antioxidant supplementation with NAC increases proliferation of CAP-treated osteosarcoma cells, implicating an involvement of redox signalling. Activation of PRXI and -2 indicate CAP affects redox homeostasis.
\end{abstract}

Osteosarcoma (OS) is the most common primary malignant bone tumour in adolescents and young adults $(1,2)$. Human OS shows a bimodal age distribution, the first in late childhood and early adulthood, and the second in adults over the age of 65 years (3). Advances in multi-agent chemotherapy regimens and refined surgical techniques have led to improved limb salvage and a 5-year survival rate of

Correspondence to: Dr. Denis Gümbel, MD, Department of Trauma, Reconstructive Surgery and Rehabilitation Medicine, Ferdinand-Sauerbruch-Str. 17475 Greifswald, Germany. Tel: +49 38348622541, e-mail: denis.guembel@uni-greifswald.de

Key Words: Osteosarcoma, cold atmospheric plasma, peroxiredoxin, antitumour efficacy, apoptosis. up to $60-70 \%$ in those with non-metastatic disease (4). However, stagnation in progress of systemic OS management has been reported, demanding for novel, individually tailored and biologically-driven treatment strategies. The latter may involve a shift in paradigm towards the use of molecularly targeted agents $(4,5)$. The highest incidence of OS being during adolescence, and more specifically at sites where the greatest increase in bone length occurs, together with recent biomolecular findings suggest molecular aberrations in cell growth as a key etiological factor (6). Current therapeutic strategies involve neoadjuvant multi-agent chemotherapy followed by radical surgical removal of tumours and postoperative adjuvant chemotherapy (2). Relative resistance to radiotherapy warrants novel treatment options, especially in cases where radical surgical en bloc resection cannot be achieved with conventional surgical techniques (7).

Beside eradication of pathogens and treatment of chronic wounds, cold atmospheric plasma (CAP) has been shown to exert anticancer effects in vitro and in vivo (8-12). Argon and helium are most commonly used as inert carrier gases in this process.

Recent studies revealed that CAP treatment attenuates tumour cell proliferation via induction of programmed cell death rather than through direct cytotoxic effects (13-15). Furthermore, in contrast to 'thermal plasma', 'non-thermal' CAP temperature ranges from $20^{\circ} \mathrm{C}$ to $50^{\circ} \mathrm{C}$, preserving molecular structures and cellular integrity, which corresponds with a lack of genotoxic potential (16). It also seems more effective on tumour cells than on normal, nonneoplastic cells $(17,18)$. However, the underlying molecular mechanisms remain not fully understood.

CAP, generated by focused electrical discharge, contains a dose-controlled mixture of highly reactive and energetic particles. Positive and negative ions, electrons, excited atoms and molecules (i.e. singlet-oxygen), free radicals such as reactive oxygen (ROS) and nitrogen species (RNS) and 
photons are delivered at the nozzle of the CAP device leading to direct cellular effects. In addition, electromagnetic fields lead to the emission of visible UV or VUV radiation. Cell death induced by CAP treatment may be triggered by an interaction with membrane structures and intracellular redox signalling through highly reactive hydrogen peroxide $\left(\mathrm{H}_{2} \mathrm{O}_{2}\right)$ generation, producing oxidative stress (19).

Peroxiredoxins (PRXs) are small (22-27 kDa), thiol-specific antioxidant enzymes contributing to cellular resistance to oxidative stress through catalysis of peroxide reduction and to maintaining intracellular peroxide homeostasis (20). To date, six isoforms have been identified in mammalian cells, exerting regulatory effects on redox signalling pathways which have been shown to be crucial for a variety of cell functions including proliferation, metabolism and apoptosis (21). PRX isoforms 1 to 6 are localized to different cellular compartments and contain redox-active cysteine residues that substrate different intracellular peroxides i.e. $\mathrm{H}_{2} \mathrm{O}_{2}$. Inactivation of PRXs is reversed through an NAPDHdependent reduction of oxidized cys-residues by thioredoxins or glutathione (22). The numerous cellular functions of PRXs include balancing of local $\mathrm{H}_{2} \mathrm{O}_{2}$ levels, regulation of transcription, immunomodulation and modulation of cytokine activity, regulation of cellular proliferation and differentiation, as well as acting as molecular chaperones. Therefore, PRXs have been suggested as potential target for the treatment of cancer, neurodegenerative and inflammatory diseases $(20,23)$. Recent evidence suggests antitumour effects of PRXs in the development of multiple carcinomas by suppressing transcription of oncogenes. On the other hand, PRXs have also been described as having pro-oncogenic properties, promoting tumorigenesis, angiogenesis and metastasis (24-30). Proteomic analysis revealed a possible application of PRX2 as a predictive biomarker of tumour response to multi-agent chemotherapy $(27,31,32)$. However, the role of multifunctional PRXs in the development of human OS has not been elucidated.

The purpose of this study was to evaluate the potential involvement of redox-specific signalling pathways in CAPinduced apoptosis of human OS cell lines U2-OS and MNNG/HOS.

\section{Materials and Methods}

Cell culture. The human OS cell lines U2-OS and MNNG/HOS (purchased from the American Type Culture Collection, Manassas, VA, USA) were propagated in Dulbecco's modified Eagle's medium (DMEM) containing $1.0 \mathrm{~g} / \mathrm{l}$ glucose supplemented with $10 \%$ foetal bovine serum, $1 \mathrm{mM}$ sodium pyruvate, and $1 \%$ penicillin/ streptomycin (all PAN Biotech, Aidenbach, Germany) in a humidified atmosphere at $5 \% \mathrm{CO}_{2}$ and $37^{\circ} \mathrm{C}$. A total of $4 \times 10^{6}$ cells were seeded on an uncoated cell culture plate. After 4 days, cells were washed twice in phosphate-buffered saline and detached using $0,1 \%$ trypsin $/ 0,04 \%$ ethylendiaminetetra-acetic acid (EDTA) and resuspended in DMEM. For antioxidant experiments, DMEM was supplemented with $5 \mathrm{mM} \mathrm{N}$-acetylcysteine (NAC; Carl Roth, Karlsruhe, Germany) or $100 \mu \mathrm{M}$ vitamin C (Carl Roth).

CAP treatment. An atmospheric plasma jet (APPJ) kINPen MED (Neoplas Tools, Greifswald, Germany) was utilized for CAP generation (carrier gas: argon, gas flow: $3 \mathrm{l} / \mathrm{min}$; supply voltage $=65 \mathrm{~V} \mathrm{DC}$; frequency: $1.1 \mathrm{MHz}$ ). A total of $4.0 \times 10^{4}$ (U2-OS) and $8.0 \times 10^{4}$ (MNNG/HOS) cells were treated for $10 \mathrm{~s}$ in suspension following a standard meandering pattern. After CAP treatment, cells were immediately transferred to poly-L-lysine (PAN Biotech)-coated 24-well cell culture plates and incubated in DMEM with or without antioxidant supplementation for 4, 12, 24, 48, 72, 96 or $120 \mathrm{~h}$. For protein analysis, $5.0 \times 10^{5}$ cells were suspended in $500 \mu \mathrm{l}$ DMEM, treated with CAP and incubated in poly-L-lysine-coated 6-well cell culture plates.

Cell proliferation assay. Viable cell count of U2-OS cells was assessed by utilizing a CASY Cell Counter and Analyzer Model TT (Roche Applied Science, Mannheim, Germany). Cells were detached at 4, 12, 24, 48, 72, 96 and 120 h by trypsin treatment and suspended in CASYton (Roche Applied Science). A 1:100 dilution, and three replicates of $400 \mu \mathrm{l}$ of cell suspension were analysed. Measurements were performed using a capillary of $150 \mu \mathrm{m}$ in diameter. The following cell line-specific gate settings were utilized to discriminate between viable, dead cells, and cellular debris: $7.20 \mu \mathrm{m} / 13.95 \mu \mathrm{m}$ for U2-OS, $7.20 \mu \mathrm{m} / 14.85 \mu \mathrm{m}$ for MNNG/HOS.

Western blotting. Cellular levels and redox state of PRX1, PRX2 and mitochondrial PRX3 were determined following $10 \mathrm{~s}$ of CAP treatment immediately and at $1 \mathrm{~h}$ after treatment. The supernatant was collected and mixed with loading buffer (0.3 M Tris $/ \mathrm{HCl}(\mathrm{pH} 7.0), 50 \%$ glycerol, $5 \%$ sodium dodecyl sulfate (SDS), $0.1 \%$ bromphenol blue) for analysis of potential secretion of PRX1 and PRX2. For intracellular PRX analysis, cell lysis was carried out using alkylating $N$-ethylmaleimide (NEM) buffer [100 mM NEM in phosphate-buffered saline (PBS)] and DPBS [40 mM HEPES (pH 7.4), $50 \mathrm{mM} \mathrm{NaCl}, 1 \mathrm{mM}$ EDTA, $1 \mathrm{mM}$ EGTA, 25× proteinase inhibitor]. After centrifugation at $93 \times g$ for $5 \mathrm{~min}$, the supernatant was discarded and the pellet was resuspended in NEM buffer $(12.5 \mu \mathrm{g} / \mu \mathrm{l}$ NEM in lysis buffer) and lysis buffer [ $10 \%$ Nonidet $^{\mathrm{TM}}$ P-40, $200 \mathrm{mM}$ EDTA, 0,2 M Tris (pH 7.5), Millipore water] including 20\% CHAPS detergent (all Roche Applied Science). Prior to SDS polyacylamide gel electrophoresis (SDS-PAGE), the total amount of protein was analysed according to Bradford. For western blot analysis, SDS-PAGE (pre-cast gels; Biorad, Munich, Germany) and stain-free technology (Biorad) was used. In order to analyse secreted PRXs in the cell culture supernatant, equal volumes were reduced with $100 \mathrm{mM}$ dithiothreitol, incubated for $30 \mathrm{~min}$ at $21^{\circ} \mathrm{C}$ and $10 \mathrm{~min}$ at $94^{\circ} \mathrm{C}$. The separation of proteins was performed by SDS-PAGE and transferred to polyvinylidene fluoride membranes (Whatman; Biorad) using the semi-dry-technique. Specific primary antibodies produced and evaluated as stated in (33) directed against PRX1-3 were used in combination with horseradish peroxidase-labelled secondary antibody (Cell Signaling Technology, Danvers, MA, USA). For protein visualization, SuperSignal West Dura Chemiluminescent Substrate (Thermo Scientific, Waltham, MA, USA) was used in a Chemidoc system (Biorad) and quantified using ImageJ software according to the manufacturer's instructions.

Statistical analysis. For statistical analysis, GraphPad Prism Version 5.0 (GraphPad Software, La Jolla, CA, USA) was employed. Data 

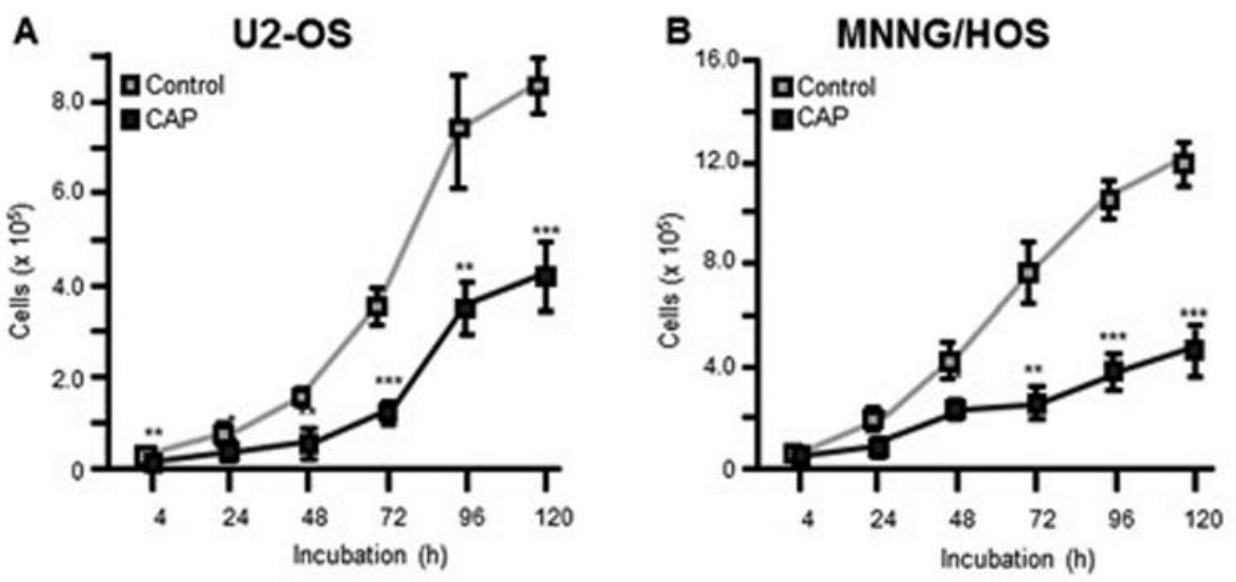

Figure 1. Cell proliferation of U2-OS and MNNG/HOS cells in an in vitro cell culture model of osteosarcoma. Viable cell counts of U2-OS (A) and $M N N G / H O S(B)$ cells following cold atmospheric plasma $(C A P)$ treatment for $10 \mathrm{~s}$. Data are given as mean $\pm S D$ of cell count. Significantly different at $* p \leq 0.05, * * p \leq 0.01$ and $*^{* *} p \leq 0.001 v$ s. control, as determined by the Student's $t$-test.

shown in the figures are either representative experiments or expressed as the mean $\pm \mathrm{SD}$ of at least five independent experiments. Significant differences between two groups were determined using the unpaired Student's $t$-test. $p$-Values of less than 0.05 were considered statistically significant.

\section{Results}

CAP treatment of osteosarcoma cells attenuates cellular proliferation. Over a period of $120 \mathrm{~h}$, control-treated U2-OS cells demonstrated characteristic cell growth. In contrast, CAP treatment of U2-OS cells showed attenuated proliferation rates (Figure 1A). In parallel MNNG/HOS cells exhibited characteristic cell growth, whereas CAP treatment also attenuated proliferation of MNNG/HOS cells (Figure 1B).

$C A P$-induced attenuation of $O S$ cell proliferation is reduced by NAC but not vitamin C supplementation. Pre-incubation of U2-OS and MNNG/HOS cells with vitamin C did not significantly influence cell proliferation. Cell proliferation of CAP-treated cells supplemented with vitamin $C$ was reduced compared to argon-treated controls treated with vitamin $\mathrm{C}$ (U2-OS: 24 h: 1.82-fold decrease, $p=0.0026 ; 48 \mathrm{~h}$ : 2.45 -fold decrease, $p=0.0112 ; 72 \mathrm{~h}: 3.17$-fold decrease, $p=0.0167 ; 96$ $\mathrm{h}$ : 4.08 -fold decrease, $p=0.0011 ; 120 \mathrm{~h}$ : 14-fold decrease, $p=0.0028$; MNNG/HOS: 4 h: 1.73 -fold decrease, $p=0.0404$; $24 \mathrm{~h}: 2.86$-fold decrease, $p \leq 0.0001 ; 48 \mathrm{~h}$ : 3-fold decrease, $p \leq 0.0001 ; 72$ h: 2.81-fold decrease, $p \leq 0.0001 ; 96$ h: 3.2 -fold decrease, $p \leq 0.0001 ; 120 \mathrm{~h}: 2.97$-fold decrease, $p \leq 0.0001$; Figure 2A and B).

Compared to untreated control cells, OS cell proliferation was also not influenced by vitamin $\mathrm{C}$ or NAC supplementation (data not shown).
In contrast to vitamin $\mathrm{C}$, supplementation of NAC to the media of CAP-treated U2-OS cells largely neutralised the antiproliferative effects of CAP. NAC-supplemented U2-OS cells showed only minimally reduced viable cell counts after CAP treatment compared to argon-treated cells with NAC supplementation (Figure 2C; U2-OS; 1.13-fold decrease, $p=0.4360 ; 24$ h: 1.33 -fold decrease, $p=0.2318 ; 48$ h: $1.56-$ fold decrease, $p=0.0447 ; 72 \mathrm{~h}: 2.13$-fold decrease, $p \leq 0.0001$; $96 \mathrm{~h}: 1.61$-fold decrease, $p=0.0181 ; 120 \mathrm{~h}: 1.28$-fold decrease, $p=0.1679$ ). In parallel $\mathrm{MNNG} / \mathrm{HOS}$ cells also exhibited only minimally reduced viable cell counts with NAC supplementation after CAP treatment compared to argon-treated cells and NAC supplementation (Figure 2D; MNNG/HOS; 4 h: 1.15 -fold decrease, $p=0.1328 ; 24$ h: 1.33 fold decrease, $p=0.1524 ; 48 \mathrm{~h}$ : 1.33 -fold decrease, $p=0.0091$; 72 h: 1.33 -fold decrease, $p=0.0004 ; 96$ h: 1.27 -fold decrease, $p=0.0765 ; 120 \mathrm{~h}$ : 1.45 -fold decrease, $p=0.0669$ ).

CAP treatment of OS cells influence intracellular PRX levels. The addition of NEM led to blocking of sulfhydryl groups after incubation and lysis in control and CAP treated cells. Western blot analysis showed no differences in overall PRX1 protein levels in U2-OS and MNNG/HOS cells (data not shown). After $10 \mathrm{~s}$ of CAP treatment differences in PRX2 and PRX3 protein levels in OS cells were detectable, although less pronounced in MNNG/HOS. CAP treatment led to an increase of intracellular PRX2 expression. The ratio of oxidized to reduced PRX1 and PRX2 assessed after $10 \mathrm{~s}$ of incubation and 1 hour of incubation (Figure 3A and B) and was significantly altered in U2-OS cells. Protein levels of the mitochondrial PRX3 in U2-OS cells were not significantly influenced. Similar results were seen in 

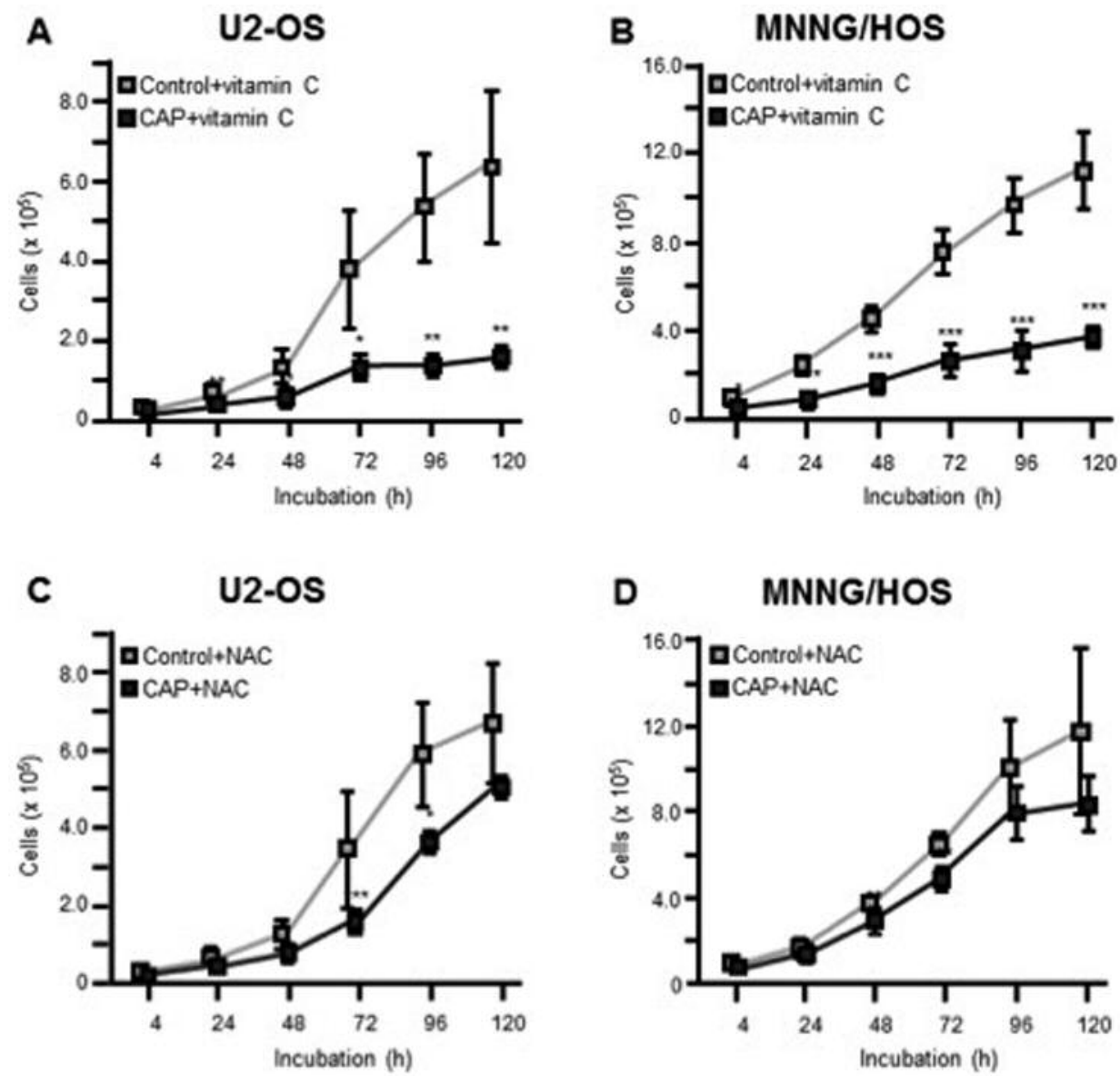

Figure 2. Effects of vitamin $C(A, B)$ and $N$-acetylcysteine $(N A C)(C, D)$ supplementation on cellular proliferation of U2-OS and MNNG/HOS cells after cold atmospheric plasma $(C A P)$ treatment. Cell proliferation was assessed at the indicated time points. Data are given as the mean $\pm S D$. Significantly different at ${ }^{*} p \leq 0.05, * * p \leq 0.01$, and ${ }^{* *} p \leq 0.001 \mathrm{vs}$. control, as determined by the Student's t-test.

MNNG-HOS/cells after 10s and $1 \mathrm{~h}$ of incubation (Figure $3 \mathrm{C}$ and D). CAP treatment of U2-OS and MNNG/HOS cells influenced the intracellular PRX profile (Figure 3).

CAP treatment of $O S$ cells influences PRX2 secretion. The secretion of PRX2 correlated with the intracellular increase of the oxidized dimer. Significant differences between control and CAP-treated cells were observed in U2-OS cells after $10 \mathrm{~s}$ (Figure 4A and B) but not in MNNG/HOS cells (Figure 4C and D). In contrast, secretion of PRX1 into the cell culture supernatant was not detected (Figure 4C and D). The mitochondrial isoform PRX3 was not detected in cell culture supernatant as expected (data not shown).

\section{Discussion}

Cellular effects of CAP have been studied in several tumour entities including prostatic, pancreatic, and lung cancer (12,
14, 34). Recent studies revealed that CAP treatment attenuates tumour cell proliferation via induction of programmed cell death rather than by direct cytotoxic effects $(13-15,35)$. In a preclinical in vitro OS model, cell proliferation was not only significantly diminished following CAP treatment, but also strong evidence suggested the induction of apoptosis (36). However, the underlying molecular mechanisms in CAP-induced apoptosis of human OS cells remain poorly understood.

Growing evidence suggests a potential involvement of reactive species such as ROS and RNS leading to DNA damage (37), lipid peroxidation (38) or mitochondrial dysfunction (39). Undoubtedly, a thorough understanding of the precise mode of action prior to introduction to clinical practice is mandatory to ensure patient safety.

Therefore, in the present study molecular effects of antioxidant supplementation on OS cell proliferation after CAP treatment were investigated hypothesising an involvement of 
A

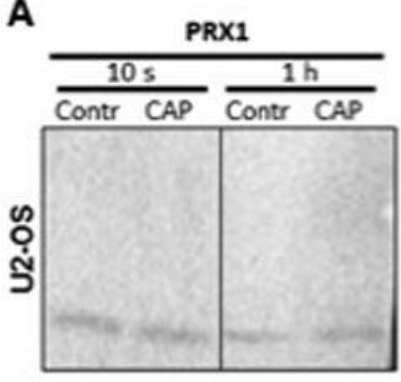

PRX2

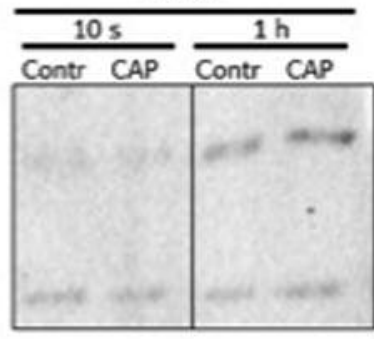

PRX3

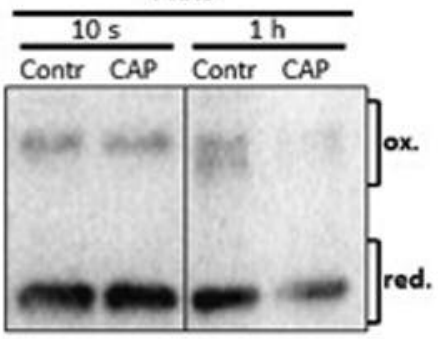

B

\begin{tabular}{|c|c|c|c|c|c|c|c|c|c|c|c|}
\hline \multicolumn{4}{|c|}{ PRX1 ox. } & \multicolumn{4}{|c|}{ PRX2 ox. } & \multicolumn{4}{|c|}{ PRX3 ox. } \\
\hline \multicolumn{2}{|c|}{$10 \mathrm{~s}$} & \multicolumn{2}{|c|}{$1 \mathrm{~h}$} & \multicolumn{2}{|c|}{$10 \mathrm{~s}$} & \multicolumn{2}{|c|}{$1 \mathrm{~h}$} & \multicolumn{2}{|c|}{$10 \mathrm{~s}$} & \multicolumn{2}{|c|}{$1 \mathrm{~h}$} \\
\hline Contr & CAP & contr & $\cos$ & Contr & CAP & Contr & CAP & Contr & CAP & Contr & CAP \\
\hline $3.6 \%$ & $9.3 \%$ & 8.15 & $13.4 \mathrm{~S}$ & $34.3 \%$ & $40.5 \%$ & $63.3 \%$ & $64.7 \%$ & $14.2 \%$ & $14.3 \%$ & $18.7 \%$ & $17.1 \%$ \\
\hline
\end{tabular}
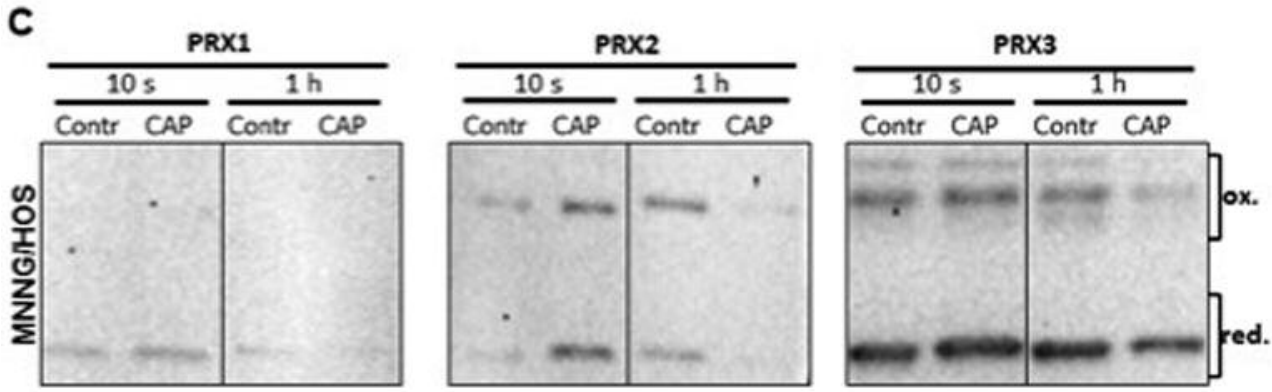

D

\begin{tabular}{|c|c|c|c|c|c|c|c|c|c|c|c|}
\hline \multicolumn{4}{|c|}{ PRX1 ox. } & \multicolumn{4}{|c|}{ PRX2 ox. } & \multicolumn{4}{|c|}{ PRX3 ox. } \\
\hline \multicolumn{2}{|c|}{$10 \mathrm{~s}$} & \multicolumn{2}{|c|}{$1 \mathrm{~h}$} & \multicolumn{2}{|c|}{$10 \mathrm{~s}$} & \multicolumn{2}{|c|}{$1 \mathrm{~h}$} & \multicolumn{2}{|c|}{$10 \mathrm{~s}$} & \multicolumn{2}{|c|}{$1 \mathrm{~h}$} \\
\hline Contr & $\cos$ & contr & $\cos$ & contr & CAP & Contr & CAP & Contr & CAP & Contr & CAP \\
\hline $4.2 \mathrm{~s}$ & $9.8 \%$ & $45 \%$ & 4.85 & $40.0 \mathrm{~N}$ & $45.2 \%$ & $66.2 \%$ & $63.1 \mathrm{~s}$ & $27.0 \%$ & $29.5 \%$ & $19.0 \%$ & $14.7 \mathrm{~s}$ \\
\hline
\end{tabular}

Figure 3. Effects of cold atmospheric plasma $(C A P)$ on intracellular peroxiredoxin (PRX) levels. The PRX redox blots represented the analyzed peroxidases PRX1, PRX2 and PRX3, showing the monomeric PRX, and oxidised, dimeric form generated during the catalytic mechanism in U2-OS (A) and MNNG/HOS (C) cell lysates. Densitometric quantification of the oxidised PRXs compared to total PRX protein (monomeric and dimeric form) in U2-OS (B) and MNNG/HOS (D) cells. ox: Oxidised, dimeric form; red: reduced, monomeric form.

redox-specific signalling pathways. Moreover, redox-specific cellular responses to CAP treatment were critically examined by quantification of intracellular expression of PRX1-3.

In accordance with the results from previous studies, CAP treatment for $10 \mathrm{~s}$ significantly mitigated cell proliferation of U2-OS and MNNG/HOS cells, leading to a reduction of viable cell counts by over $60 \%$ after $120 \mathrm{~h}$ of incubation. Both cell lines are widely accepted human OS cell culture models.

In order to investigate the potential involvement of redoxspecific signalling pathways, antioxidants vitamin $\mathrm{C}$ and NAC were added to the cell suspension. Interestingly, NAC but not vitamin $C$ supplementation significantly reduced the observed effect of CAP. NAC serves as a precursor for the biological antioxidant glutathione (GSH), which in turn is essential for a cell's redox homeostasis. GSH and regulatory glutathione-Stransferase P1 (GSTP1) have been shown to play a major role in the resistance of OS to chemotherapy (40). Thus, CAP treatment may be particularly effective in chemotherapyresistant OS where surgical en bloc resection cannot be achieved. Moreover, CAP treatment may be a promising cotherapy to prevent chemoresistance mechanisms during conventional chemotherapy.

Intracellular and extracellular effects on PRX redox state and secretion suggest an increased oxidation of PRX1 and PRX2, which could result in antiproliferative signalling cascades including programmed cell death (41). Furthermore, 

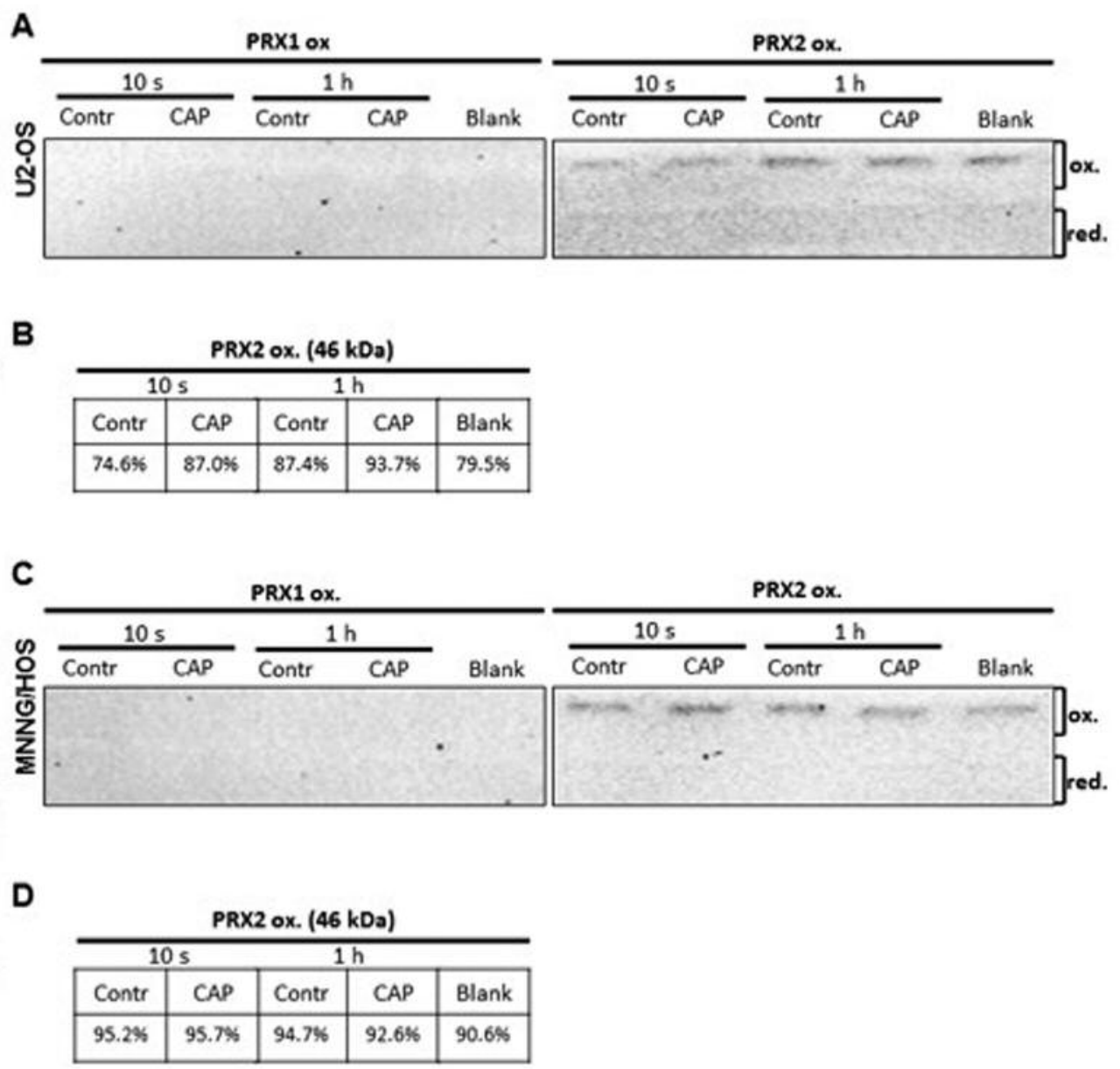

Figure 4. Effects of cold atmospheric plasma (CAP) on the secretion of peroxiredoxins (PRXs). Protein levels of PRX1 and PRX2 of control-and CAP-treated U2-OS (A) and MNNG/HOS (C) cells. PRX2 secretion was compared to total PRX protein (monomeric and dimeric form) in U2-OS (B) and MNNG/HOS (D) cell culture supernatant. ox: Oxidised, dimeric form; red: reduced, monomeric form; Blank: blank value, cell culture medium without cell contact.

PRX2 secretion was significantly increased following CAP treatment. Molecular and cellular functionality of secreted extracellular PRX proteins, however, are still unexplained.

As $\mathrm{H}_{2} \mathrm{O}_{2}$ plays crucial role in biological CAP effects (42) PRX oxidation and subsequent cellular redox signalling may be induced by CAP-induced $\mathrm{H}_{2} \mathrm{O}_{2}$ formation. The reactive compound may be endogenously produced as a result of CAP treatment and, more likely, exogenous $\mathrm{H}_{2} \mathrm{O}_{2}$ may be directly introduced into the cellular system by CAP itself. The kINPenMED applied in this study has been characterised as a significant source of $\mathrm{H} 2 \mathrm{O} 2$ (42). Notably, effects of CAP treatment were specifically restricted to PRX1 and PRX2, whereas PRX3, which is also part of the glutathione system but exclusively expressed in the mitochondria, were not affected by CAP (43).

The results of the current study underline the involvement of redox-specific signalling pathways in CAP-induced apoptosis of human OS. Future studies should further specify the involved mechanisms and evaluate the effects of different exposure times.

\section{Acknowledgements}

No funding was received for the study. None of the Authors stated a conflict of interest in regard to this study.

The Authors thank Anne Brandenburg and Katja Wittig for excellent technical assistance.

\section{References}

1 Stiller CA, Bielack SS, Jundt G and Steliarova-Foucher E: Bone tumours in European children and adolescents, 19781997. Report from the Automated Childhood Cancer Information System project. Eur J Cancer 42(13): 2124-2135, 2006. 
2 Luetke A, Meyers PA, Lewis I and Juergens H: Osteosarcoma treatment - where do we stand? A state of the art review. Cancer Treat Rev 40(4): 523-532, 2014.

3 Mirabello L, Troisi RJ and Savage SA: Osteosarcoma incidence and survival rates from 1973 to 2004: data from the Surveillance, Epidemiology, and End Results Program. Cancer 115(7): 1531-1543, 2009.

4 Allison DC, Carney SC, Ahlmann ER, Hendifar A, Chawla S, Fedenko A, Angeles C and Menendez LR: A meta-analysis of osteosarcoma outcomes in the modern medical era. Sarcoma 2012: 704872, 2012.

5 Carrle D and Bielack SS: Current strategies of chemotherapy in osteosarcoma. Int Orthop 30(6): 445-451, 2006

6 Fuchs B and Pritchard DJ: Etiology of osteosarcoma. Clin Orthop Relat Res 397: 40-52, 2002.

7 Schwarz R, Bruland O, Cassoni A, Schomberg P and Bielack S: The role of radiotherapy in osteosarcoma. Cancer Treat Res 152: 147-164, 2009.

8 Kramer A, Bekeschus S, Matthes R, Bender C, Stope MB, Napp M, Lademann O, Lademann J, Weltmann KD and Schauer F: Cold physical plasmas in the field of hygiene-relevance, significance, and future applications. Plasma Processes and Polymers 12(12): 1410-1422, 2015.

9 Kramer A, Lademann J, Bender C, Sckell A, Hartmann B, Münch S, Hinz P, Ekkernkamp A, Matthes R and Koban I: Suitability of tissue tolerable plasmas (TTP) for the management of chronic wounds. Clinical Plasma Medicine 1(1): 11-18, 2013.

10 Heslin C, Boehm D, Milosavljevic V, Laycock M, Cullen P and Bourke P: Quantitative assessment of blood coagulation by cold atmospheric plasma. Plasma Medicine 4(1-4): 153-163, 2014.

11 Welz C, Emmert S, Canis M, Becker S, Baumeister P, Shimizu T, Morfill GE, Harréus U and Zimmermann JL: Cold atmospheric plasma: a promising complementary therapy for squamous head and neck cancer. PLoS One 10(11): e0141827, 2015.

12 Partecke LI, Evert K, Haugk J, Doering F, Normann L, Diedrich S, Weiss FU, Evert M, Huebner NO, Guenther C, Heidecke CD, Kramer A, Bussiahn R, Weltmann KD, Pati O, Bender C and von Bernstorff W: Tissue tolerable plasma (TTP) induces apoptosis in pancreatic cancer cells in vitro and in vivo. BMC Cancer 12: 4732012, 2012.

13 Weiss M, Gümbel D, Hanschmann EH, Mandelkow R, Gelbrich $\mathrm{N}$, Zimmermann U, Walther R, Ekkernkamp A, Sckell A, Kramer A, Burchardt M, Lillig $\mathrm{CH}$ and Stope MB: Cold atmospheric plasma treatment induces anti-proliferative effects in prostate cancer cells by redox and apoptotic signaling pathways. PLoS One 10(7): e0130350, 2015.

14 Weiss M. Gümbel D, Gelbrich N, Brandenburg LO, Mandelkow R, Zimmermann U, Ziegler P, Burchardt M and Stope MB: Inhibition of Cell Growth of the Prostate Cancer Cell Model LNCaP by Cold Atmospheric Plasma. In Vivo 29(5): 611-616, 2015.

15 Wang M, Holmes B, Cheng X, Zhu W, Keidar M and Zhang LG: Cold atmospheric plasma for selectively ablating metastatic breast cancer cells. PLoS One 8(9): e73741, 2013.

16 Kluge S, Bekeschus S, Bender C, Benkhai H, Sckell A, Below $\mathrm{H}$, Stope MB and Kramer A: Investigating the Mutagenicity of a Cold Argon-Plasma Jet in an HET-MN Model. PLoS One 11(9): e0160667, 2016.
17 Siu A, Volotskova O, Cheng X, Khalsa SS, Bian K, Murad F, Keidar $M$ and Sherman JH: Differential Effects of Cold Atmospheric Plasma in the Treatment of Malignant Glioma. PLoS One 10(6): e0126313, 2015.

18 Guerrero-Preston R, Ogawa T, Uemura M, Shumulinsky G, Valle BL, Pirini F, Ravi R, Sidransky D, Keidar M and Trink B: Cold atmospheric plasma treatment selectively targets head and neck squamous cell carcinoma cells. Int J Mol Med 34(4): 941-946, 2014.

19 Xu D, Liu D, Wang B, Chen C1, Chen Z, Li D, Yang Y, Chen $\mathrm{H}$ and Kong MG: In Situ $\mathrm{OH}$ Generation from $\mathrm{O}_{2}-$ and $\mathrm{H}_{2} \mathrm{O}_{2}$ Plays a Critical Role in Plasma-Induced Cell Death. PLoS One 10(6): e0128205, 2015.

20 Park MH, Jo M, Kim YR, Lee CK and Hong JT: Roles of peroxiredoxins in cancer, neurodegenerative diseases and inflammatory diseases. Pharmacol Ther 163: 1-23, 2016.

21 Wood ZA, Poole LB and Karplus PA: Peroxiredoxin evolution and the regulation of hydrogen peroxide signaling. Science 300(5619): 650-653, 2003.

22 Monteiro G, Horta BB, Pimenta DC, Augusto O and Netto LE: Reduction of 1-Cys peroxiredoxins by ascorbate changes the thiol-specific antioxidant paradigm, revealing another function of vitamin C. Proc Natl Acad Sci USA 104(12): 4886-91, 2007.

23 Palande KK, Beekman R, van der Meeren LE, Beverloo HB, Valk PJ and Touw IP: The antioxidant protein peroxiredoxin 4 is epigenetically down regulated in acute promyelocytic leukemia. PLoS One 6(1): e16340, 2011.

24 Jiang L, Xiao X, Ren J, Tang Y, Weng H, Yang Q, Wu M and Tang W: Proteomic analysis of bladder cancer indicates PRX-I as a key molecule in BI-TK/GCV treatment system. PLoS One 9(6): e98764, 2014.

25 Cao J, Schulte J, Knight A, Leslie NR, Zagozdzon A, Bronson R, Manevich Y, Beeson C and Neumann CA: Prdx1 inhibits tumorigenesis via regulating PTEN/AKT activity. EMBO J 28(10): 1505-1517, 2009.

26 Egler RA, Fernandes E, Rothermund K, Sereika S, de SouzaPinto N, Jaruga P, Dizdaroglu $M$ and Prochownik EV: Regulation of reactive oxygen species, DNA damage, and c-Myc function by peroxiredoxin 1. Oncogene 24(54): 8038-8050, 2005.

$27 \mathrm{Hu}$ JX, Gao Q and Li L: Peroxiredoxin 3 is a novel marker for cell proliferation in cervical cancer. Biomed Rep 1(2): 228-230, 2013.

28 Jiang H, Wu L, Mishra M, Chawsheen HA and Wei Q: Expression of peroxiredoxin 1 and 4 promotes human lung cancer malignancy. Am J Cancer Res 4(5): 445-460, 2014.

$29 \mathrm{Kim} \mathrm{TH}$, Song J, Alcantara Llaguno SR, Murnan E, Liyanarachchi S, Palanichamy K, Yi JY, Viapiano MS, Nakano I, Yoon SO, Wu H, Parada LF and Kwon CH: Suppression of peroxiredoxin 4 in glioblastoma cells increases apoptosis and reduces tumor growth. PLoS One 7(8): e42818, 2012.

30 Taniuchi K, Furihata M, Hanazaki K, Iwasaki S, Tanaka K, Shimizu T, Saito M and Saibara T: Peroxiredoxin 1 promotes pancreatic cancer cell invasion by modulating p38 MAPK activity. Pancreas 44(2): 331-340, 2015.

31 Kubota D, Mukaihara K, Yoshida A, Tsuda H, Kawai A and Kondo T: Proteomics study of open biopsy samples identifies peroxiredoxin 2 as a predictive biomarker of response to induction chemotherapy in osteosarcoma. J Proteomics 91: 393404, 2013. 
32 Quan C, Cha EJ, Lee HL, Han KH, Lee KM and Kim WJ: Enhanced expression of peroxiredoxin I and VI correlates with development, recurrence and progression of human bladder cancer. J Urol 175(4): 1512-1516, 2006.

33 Godoy JR, Funke M, Ackermann W, Haunhorst P, Oesteritz S, Capani F, Elsässer HP and Lillig CH: Redox atlas of the mouse. Immunohistochemical detection of glutaredoxin-, peroxiredoxin, and thioredoxin-family proteins in various tissues of the laboratory mouse. Biochim Biophys Acta 1810(1): 2-92, 2011.

34 Kim JY, Ballato J, Foy P, Hawkins T, Wei Y, Li J and Kim SO: Apoptosis of lung carcinoma cells induced by a flexible optical fiber-based cold microplasma. Biosens Bioelectron 28(1): 333 338,2011

35 Schuster M, Seebauer C, Rutkowski R, Hauschild A, Podmelle F, Metelmann C, Metelmann B, von Woedtke T, Hasse S, Weltmann KD and Metelmann HR: Visible tumor surface response to physical plasma and apoptotic cell kill in head and neck cancer. J Craniomaxillofac Surg 44(9): 1445-1452, 2016.

36 Gümbel D, Gelbrich N, Weiss M, Napp M, Daeschlein G, Sckell A, Ender SA, Kramer A, Burchardt M, Ekkernkamp A and Stope MB: New treatment options for osteosarcoma - inactivation of osteosarcoma cells by cold atmospheric plasma. Anticancer Res 36(11): 5915-5922, 2016.

37 Kalghatgi S, Kelly CM, Cerchar E, Torabi B, Alekseev O, Fridman A, Friedman G and Azizkhan-Clifford J: Effects of nonthermal plasma on mammalian cells. PLoS One 6(1): e16270, 2011.

38 Brun P, Pathak S, Castagliuolo I, Palù G, Brun P, Zuin M, Cavazzana $R$ and Martines E: Helium generated cold plasma finely regulates activation of human fibroblast-like primary cells. PLoS One 9(8): e104397, 2014.
39 Panngom K, Baik KY, Nam MK, Han JH, Rhim H and Choi EH: Preferential killing of human lung cancer cell lines with mitochondrial dysfunction by nonthermal dielectric barrier discharge plasma. Cell Death Dis 4: e642, 2013.

40 Huang G, Mills L and Worth LL: Expression of human glutathione S-transferase P1 mediates the chemosensitivity of osteosarcoma cells. Mol Cancer Ther 6(5): 1610-1619, 2013.

41 Hanschmann EM, Godoy JR, Berndt C, Hudemann C and Lillig $\mathrm{CH}$ : Thioredoxins, glutaredoxins, and peroxiredoxins molecular mechanisms and health significance: from cofactors to antioxidants to redox signaling. Antioxid Redox Signal 19(13): 1539-1605, 2013.

42 Bekeschus S, Kolata J, Winterbourn C, Kramer A, Turner R, Weltmann KD, Bröker B and Masur K: Hydrogen peroxide: A central player in physical plasma-induced oxidative stress in human blood cells. Free Radic Res 48(5): 542-549, 2014.

43 Zhang H, Go YM and Jones DP: Mitochondrial thioredoxin2/peroxiredoxin-3 system functions in parallel with mitochondrial GSH system in protection against oxidative stress. Arch Biochem Biophys 465(1): 119-126, 2007.
Received January 12, 2017

Revised February 24, 2017

Accepted February 28, 2017 